\title{
Midlatitude cirrus classification at Rome Tor Vergata through a multichannel Raman-Mie-Rayleigh lidar
}

\author{
D. Dionisi ${ }^{1,2}$, P. Keckhut ${ }^{1}$, G. L. Liberti ${ }^{2}$, F. Cardillo ${ }^{2}$, and F. Congeduti ${ }^{2}$ \\ ${ }^{1}$ Laboratoire Atmosphères, Milieux, Observations Spatiales-IPSL, UMR8190, CNRS/INSU, UVSQ-UPMC, \\ UniverSud Paris, Guyancourt, France \\ ${ }^{2}$ Istituto di Scienze dell' Atmosfera e del Clima, Consiglio Nazionale delle Ricerche, Rome, Italy
}

Correspondence to: D. Dionisi (davide.dionisi@latmos.ipsl.fr)

Received: 6 March 2013 - Published in Atmos. Chem. Phys. Discuss.: 11 April 2013

Revised: 25 October 2013 - Accepted: 30 October 2013 - Published: 9 December 2013

\begin{abstract}
A methodology to identify and characterize cirrus clouds has been developed and applied to the multichannelmultiwavelength Rayleigh-Mie-Raman (RMR) lidar in Rome Tor Vergata (RTV). A set of 167 cirrus cases, defined on the basis of quasi-stationary temporal period conditions, has been selected in a data set consisting of about $500 \mathrm{~h}$ of nighttime lidar sessions acquired between February 2007 and April 2010. The derived lidar parameters (effective height, geometrical and optical thickness and mean back-scattering ratio) and the cirrus mid-height temperature (estimated from the radiosonde data of Pratica di Mare, WMO, World Meteorological Organization, site no. 16245) of this sample have been analyzed by the means of a clustering multivariate analysis. This approach identified four cirrus classes above the RTV site: two thin cirrus clusters in mid- and upper troposphere and two thick cirrus clusters in mid-upper troposphere. These results, which are very similar to those derived through the same approach at the lidar site of the Observatoire de Haute-Provence (OHP), allows characterization of cirrus clouds over the RTV site and attests to the robustness of such classification.
\end{abstract}

To acquire some indications about the cirrus generation methods for the different classes, analyses of the extinctionto-backscatter ratio (lidar ratio, $\mathrm{LR}_{\text {eff }}$ ), in terms of frequency distribution functions and dependencies on the mid-height cirrus temperature, have been performed. A preliminary study relating some meteorological parameters (e.g., relative humidity, wind components) to cirrus clusters has also been conducted.

The RTV cirrus results, recomputed through the cirrus classification by Sassen and Cho (1992), show good agree- ment with other midlatitude lidar cirrus observations for the relative occurrence of subvisible (SVC), thin and opaque cirrus classes $(10 \%, 49 \%$ and $41 \%$, respectively). The overall mean value of cirrus optical depth is $0.37 \pm 0.18$, while most retrieved $L_{\text {eff }}$ values range between 10-60 sr, and the estimated mean value is $31 \pm 15 \mathrm{sr}$, similar to $L R$ values of lower latitude cirrus measurements.

The obtained results are consistent with previous studies conducted with different systems and confirm that cirrus classification based on a statistical approach seems to be a good tool both to validate the height-resolved cirrus fields calculated by models and to investigate the key processes governing cirrus formation and evolution. However, the lidar ratio and optical depth analyses are affected by some uncertainties (e.g., lidar error noise, multiple scattering effects, supercooled water clouds) that reduce the confidence of the results. Future studies are needed to improve the characterization of the cirrus optical properties and, thus, the determination of their radiative impact.

\section{Introduction}

Despite extensive research dedicated to cirrus observations in conjunction with relevant parameters (temperature, humidity, aerosols, wind, waves, etc.) in the last decades, the report of the International Panel for Climate Change (IPCC, Solomon et al., 2007) demonstrated that the estimation of cirrus radiative impact is still one of the largest sources of uncertainty in global climate models (GCMs) parameterizations. Furthermore, the exact role of the different parameters in the 
formation of cirrus clouds is not well known (Lohmann et al., 2004). To understand the effects of this type of clouds on the earth's climate, it is necessary to observe and characterize their properties. In particular, cirrus vertical distributions determine their local cooling or warming effects (Khvorostyanov and Sassen, 2002). Climate models are sensitive to even small changes in the cirrus coverage and the numerical representation of cirrus in GCMs were not accurately constrained by available satellite data (Zhang et al., 2005) before the recent use of space-borne lidar measurements (Chepfer et al., 2008). Furthermore, in situ observations constitute a demanding and expensive operation and cannot provide a representative database to derive consistent cirrus climatology. In summary, in GCM cloud prognostic schemes, there are still open questions regarding cirrus. These issues are related to both a lack of reliable observations and to the shortcomings of the forecast models to simulate ice clouds (Immler et al., 2008).

Lidar technique can detect cirrus with high spatial and temporal resolution, providing accurate information on their vertical distribution that can be used to develop highly resolved cirrus databases. In particular, lidar measurements give access to cirrus boundaries, vertical thickness (with resolution of 10 to $100 \mathrm{~m}$ ), optical depth and cirrus backscattering ratio, all of which are related to the number of particles, their size distribution, shape, particle habit and phase.

In the last two decades the observation and characterization of cirrus clouds through the lidar technique have been largely performed in several regions of the globe both in terms of campaigns and regular observations (Sassen and Campbell, 2001; Goldfarb et al., 2001; Wang and Sassen, 2002; Immler et al., 2002; Seifert et al., 2007).

Since 2006, cirrus clouds are continuously and globally monitored through Cloud-Aerosol Lidar with Orthogonal Polarization (CALIOP) installed on Cloud-Aerosol Lidar and Infrared Pathfinder Satellite Observations (CALIPSO) satellite. These observations are largely exploited in tropical regions (Haladay et al., 2009; Sassen et al., 2009; Riihimaki et al., 2010), where cloud vertical distribution is not well known. At midlatitude, lidar cirrus information seems to be consistent whether acquired from ground or space (Dupont et al., 2010). Although the frequency of occurrence of cirrus clouds is lower at midlatitude than in the tropics, it is important to accurately characterize their vertical distribution and understand associated processes of formation and evolution in order to properly take them into account in climate numerical models.

Based on the optical depth $(\tau)$, the classification scheme of Sassen and Cho (1992) divides cirrus into subvisible (SVC), thin and opaque $(\tau<0.03,0.03<\tau<0.3$ and $\tau>0.3$, respectively). A lidar climatology of midlatitude cirrus in Utah has been derived by Sassen and Campbell (2001). In this work, detected cirrus were related to three different weather patterns: zonal jet stream flow, strong amplitude ridge, and cases of split-jet flow. However, the link between these patterns and the processes of cirrus formation is difficult to deduce.

Recent research projects performed through the lidar at Observatoire de Haute-Provence (OHP) have aimed to use lidar database to characterize midlatitude cirrus. In particular, statistical description of cirrus clouds at midlatitude was derived (Goldfarb et al., 2001) and three distinct cirrus classes with different optical properties were identified (Keckhut et al., 2006).

This type of classification could be useful both for the validation of height-resolved cirrus fields as reproduced by models and for the investigation of the key processes controlling cirrus formation and evolution. In fact, any parameterization of cirrus clouds should take into account the generating mechanism of cirrus to well characterize cirrus optical properties (Whiteman et al., 2004) and their radiative impact. The French analyses suggested that cirrus morphologies can be linked to the mechanisms of their formation.

The present study conducted with the lidar system located at Rome Tor Vergata (RTV) fits within this context. In fact, our aim has been to utilize the lidar database acquired independently for other purposes (i.e., Raman water vapor measurements in troposphere and Rayleigh/Raman temperature measurements in upper atmosphere) to derive information on cirrus clouds. In fact, although the multichannel configuration of the Rayleigh-Mie-Raman (RMR) lidar is well suited to characterize cirrus clouds, before this work this system was never applied to this type of study. Furthermore, the only detailed study on cirrus clouds conducted above this region (i.e., central Italy) was the work of Gobbi et al. (2004), which provided the first statistics of cirrus occurrence during one year of lidar data over RTV sites but without discriminating the types of the observed cirrus.

Given these considerations, the objective of the present study has been to adapt and apply a methodology to identify and characterize cirrus, using measurements of RMR lidar system. The statistical procedure adopted is based on a clustering multivariate analysis previously developed for lidar cirrus observation at OHP (Keckhut et al., 2006). This approach has been applied to approximately $500 \mathrm{~h}$ of nighttime lidar sessions acquired between February 2007 and April 2010 by the the RMR lidar system.

The obtained results and their comparison to those derived by the OHP lidar permitted both to characterize the cirrus over the RTV site and to verify the robustness of OHP climatology, given that only $600 \mathrm{~km}$ separate both sites.

With the objective of analyzing the optical properties of the identified classes, a subsample of the cirrus observation was then studied in terms of the lidar ratio (i.e., the extinction-to-backscatter ratio). Finally, the RTV cirrus results were computed through the Sassen and Cho classification and compared to other midlatitude lidar cirrus data sets.

The paper is organized as follows: Sect. 2 consists of a brief summary of the characteristics of the RMR channels used for this study and a detailed description of the cirrus 
retrieval algorithms developed and applied to the RTV lidar data. Section 3 addresses the multivariate clustering method and the results obtained. In particular, cirrus classification at RTV is presented, compared to the OHP, and then a subsample of cirrus classes are characterized and discussed in terms of their lidar parameters and are related to some meteorological variables (e.g., relative humidity, wind components) derived by radiosonde data. Finally, in Sect. 4, the results and the perspectives of this approach are summarized.

\section{Instrument and cirrus retrieval algorithm description}

\subsection{The Rayleigh-Mie-Raman lidar system}

The RMR lidar located in the suburban area of Rome $\left(41.8^{\circ} \mathrm{N}, 12.6^{\circ} \mathrm{E}\right.$, and $107 \mathrm{~m}$ altitude), at the Institute of Atmospheric Sciences and Climate (ISAC), utilizes a Nd : YAG laser with second and third harmonics generators that emits two pulsed beams in the green $(532.2 \mathrm{~nm}, 200 \mathrm{~mJ}$ energy per pulse) and in the UV (354.8 nm, $400 \mathrm{~mJ}$ energy per pulse), with $10 \mathrm{~Hz}$ repetition rate and $\sim 7 \mathrm{~ns}$ pulse width. The green beam is used to receive the elastic backscatter from the air molecules and aerosol particles; the UV beam is used only to obtain Raman backscattering signals from water vapor (WV) and nitrogen molecules and to calculate WV mixing ratio. An elastic detection channel at $355 \mathrm{~nm}$ has been recently implemented (August 2013), but the lidar measurements obtained through this new system configuration are not included in the RTV data set (February 2007-April 2010) analyzed in this study. A multiple telescope configuration, shown in Fig. 1, is adopted in the receiver to collect the signal return from different altitude layers. A detailed description of the system is reported in Congeduti et al. (1999) and in Dionisi et al. (2010), and only the characteristics of channels used in this work are described here. A $15 \mathrm{~cm}$ aperture telescope, addressed to sense troposphere $(0.5-14 \mathrm{~km})$, has been used to collect $532 \mathrm{~nm}$ elastic backscattered signal, whereas the $387 \mathrm{~nm}$ nitrogen Raman signal has been acquired through the employment of a $30 \mathrm{~cm}$ telescope (lower channel) and an array of nine $50 \mathrm{~cm}$ telescopes (upper channel). Data merging between these two channels have been obtained as follows: due to the effect of the chopper installed in the upper channel, below $7 \mathrm{~km}$ data from the lower channel are selected; between 7 and $9 \mathrm{~km}$ data are selected, considering the channel with the largest SNR; above $9 \mathrm{~km}$ only data acquired by the upper channel are considered. The acquisition vertical and temporal resolutions are, respectively, $75 \mathrm{~m}$ and $1 \mathrm{~min}$. The characteristics of the system are summarized in Table 1.

\subsection{Cirrus principal parameters}

Using lidar data mainly derived by the elastic channel at $532 \mathrm{~nm}(30 \mathrm{~cm}$ telescope $)$ and the nitrogen Raman upper channel at 387 (nine $50 \mathrm{~cm}$ telescopes), the developed procedure allows characterizing cirrus through 5 lidar principal parameters: height of cirrus boundaries ( $z_{\text {top }}$ and $\left.z_{\text {bottom }}\right)$, the geometrical $\left(\mathrm{d} z=z_{\text {top }}-z_{\text {bottom }}\right)$ and optical $(\mathrm{d} \tau)$ depth and the backscattering ratio profile (SR). The last term is defined by the expression

$\operatorname{SR}(\lambda, z)=\frac{\beta_{\mathrm{aer}}(\lambda, z)+\beta_{\mathrm{mol}}(\lambda, z)}{\beta_{\mathrm{mol}}(\lambda, z)}$,

where $\beta_{\text {aer }}$ and $\beta_{\mathrm{mol}}$ are the backscattering coefficients due to aerosol and molecules.

Using the ratio of the elastic $S\left(\lambda_{0}\right)$ and Raman nitrogen $S\left(\lambda_{\mathrm{N}}\right)$ backscattered lidar signals at two different heights $(z$ and $z_{0}$ with $z>z_{0}$ ) and assuming that $\beta_{\text {aer }} \ll \beta_{\text {mol }}$ at $z_{0}$ (clear air condition), it has been demonstrated (Ansmann et al., 1992) that

$$
\begin{aligned}
& \frac{S\left(\lambda_{0}, z\right) \cdot S\left(\lambda_{\mathrm{N}}, z_{0}\right)}{S\left(\lambda_{\mathrm{N}}, z\right) \cdot S\left(\lambda_{0}, z_{0}\right)} \cdot \frac{1}{\tau_{\mathrm{diff}}^{\mathrm{mol}}\left[z_{0}: z\right]} \\
& =\frac{\beta_{\mathrm{aer}}\left(\lambda_{0}, z\right)+\beta_{\mathrm{mol}}\left(\lambda_{0}, z\right)}{\beta_{\mathrm{mol}}\left(\lambda_{0}, z\right)} \cdot \tau_{\mathrm{diff}}^{\mathrm{aer}}\left[z_{0}: z\right] \approx \mathrm{SR}(z) .
\end{aligned}
$$

In our case, $\tau_{\text {diff }}^{\text {mol }}\left[z_{0}: z\right]$, which describes the molecular differential transmission between the laser emitted $\left(\lambda_{0}\right)$ and the received Raman nitrogen $\left(\lambda_{\mathrm{R}}\right)$ wavelength at $z_{0}$ and at $z$, is determined from radiosonde data. Since the aerosol differential transmission term, $\tau_{\text {diff }}^{\text {aer }}\left[z_{0}: z\right]$, can be approximated to be equal to 1 outside (in the case of negligible aerosol background) and inside (ice particle scattering, Van de Hulst, 1957) the cirrus, the first term in Eq. (2) is equal to SR.

Cirrus boundaries are identified applying the so-called discrete wavelet transform (DWT), using a zero-order wavelet (Haar function). This function, usually adopted for planet boundary layer (PBL) studies (Brooks, 2003 and Haij et al., 2007), is defined by the following equation:

$h\left(\frac{z-b}{b}\right)=\left\{\begin{array}{l}1: b-\frac{a}{2} \leq z<b \\ -1: b<z \leq b+\frac{a}{2}, \\ 0: \text { elswhere }\end{array}\right.$

where $a$ and $b$ are, respectively, the width and the dilation (the point where the function is centered) of the wavelet. The coefficients $W_{\mathrm{B}}(a, b)$, which are the results of the convolution between SR and $h$, are:

$W_{\mathrm{B}}(a, b, z)=a^{-1} \int_{z+a / 2}^{z-a / 2} \mathrm{SR}\left(\lambda, z^{\prime}\right) \cdot h\left(\frac{z^{\prime}-b}{a}\right) \mathrm{d} z^{\prime}$.

If SR is in phase (anti-phase) with the Haar wavelet, the convolution product shows a maximum (minimum), and these points can be used to determine the inflection points of the $\mathrm{SR}$, which, in turn, correspond to the bottom (top) of the cirrus.

Figure 2 shows the application of this technique to the case of cirrus observed during the night of 5 July 2012. In the right panel, the SR profile, integrated for $42 \mathrm{~min}$, is reported, while the corresponding $W_{\mathrm{B}}(a, b, z)$ is depicted in the left panel. 

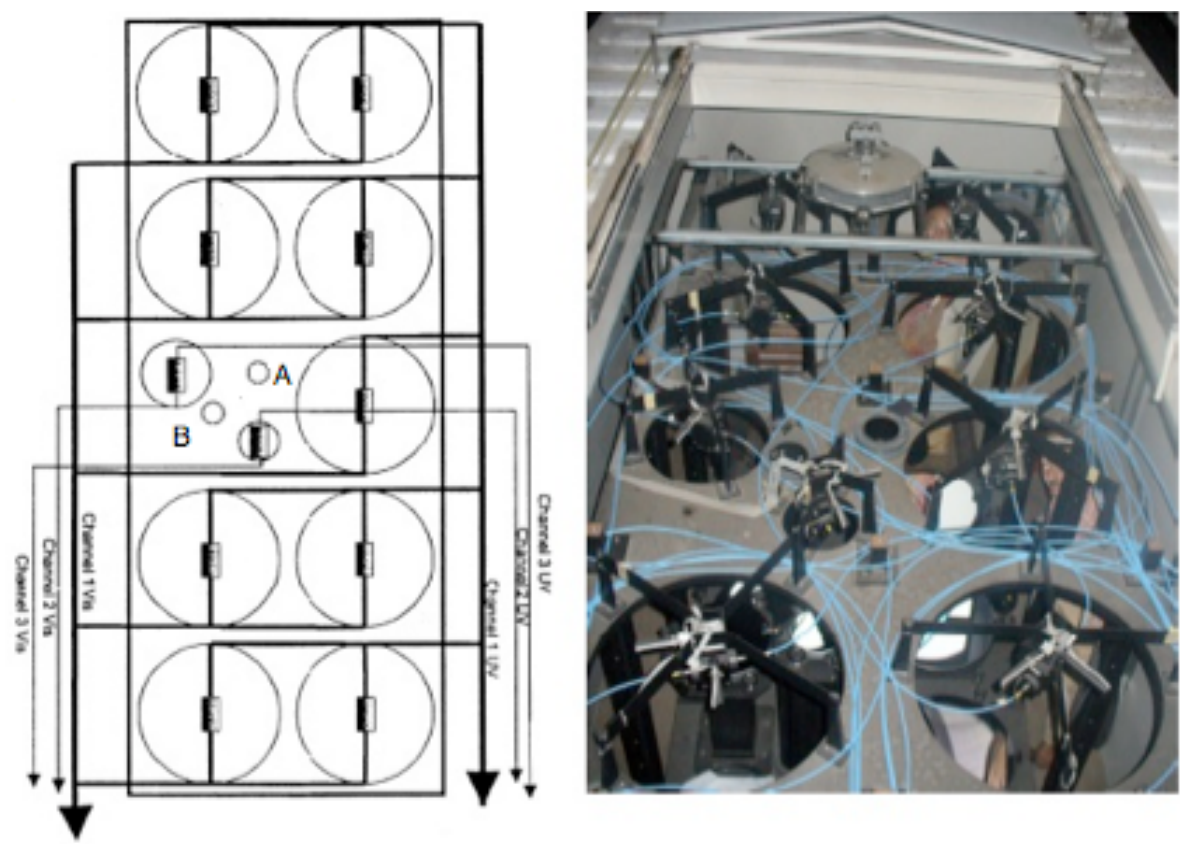

Fig. 1. Diagram of the RMR receiving channels (left) with their corresponding bird's eye view (right). A and B in the diagram (left) are the exit holes for the upward laser beam at 532 and $355 \mathrm{~nm}$, respectively.

Rome $070714(21: 23-22: 05$ UT)
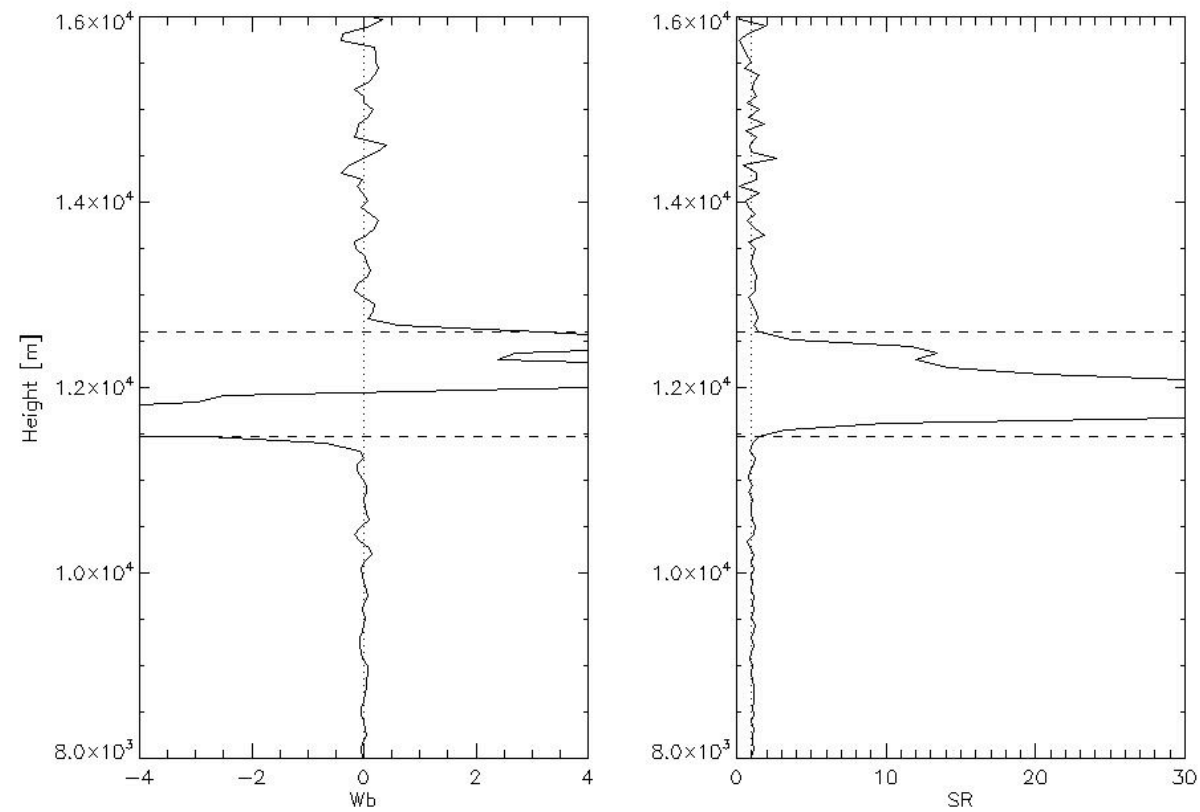

Fig. 2. SR $(z)$ profile (right panel) for a cirrus observed during the night of 5 July 2012, between 09:23 and 10:05 UT, with the corresponding $W_{\mathrm{b}}(z)$ profile. The dashed horizontal lines in the left panel mark the inflection points of $W_{\mathrm{b}}$ to which correspond the bottom (11469 m) and the top $(12519 \mathrm{~m})$ of the cirrus in the right panel. 
Table 1. Transmitter and receiver characteristics of the RTV lidar system.

\begin{tabular}{|c|c|c|c|}
\hline & \multicolumn{3}{|c|}{$\operatorname{RTV}\left(41.8^{\circ} \mathrm{N}, 12.6^{\circ} \mathrm{E}, 107 \mathrm{~m}\right.$ a.s.l $)$} \\
\hline Transmitter & & & \\
\hline $\begin{array}{l}\text { Laser type } \\
\text { Wavelength } \\
\text { Energy per pulse } \\
\text { Pulse repetition rate } \\
\text { beam diameter } \\
\text { beam divergence }\end{array}$ & & $\begin{array}{c}\mathrm{Nd}: \mathrm{YAG} \\
532 \mathrm{~nm}-355 \mathrm{~nm} \\
200 \mathrm{~mJ}-400 \mathrm{~mJ} \\
10 \mathrm{~Hz} \\
45 \mathrm{~mm} \\
0.1 \mathrm{mrad}\end{array}$ & \\
\hline Receiver & Collector 1 & Collector 2 & Collector 3 \\
\hline $\begin{array}{l}\text { Type of telescope } \\
\text { Diameter, f-number } \\
\text { Field of view (mrad) } \\
\text { Optic fiber } \\
\text { Data acquisition } \\
\text { Raman channels N2 } \\
\mathrm{H}_{2} \mathrm{O} \\
\text { Elastic channels } \\
\text { Sounding range }(\mathrm{km})\end{array}$ & $\begin{array}{r}387 \mathrm{~nm} \\
407 \mathrm{~nm} \\
532 \mathrm{~nm} \\
2-15 \text { (Raman) } \\
25-80 \text { (elastic) }\end{array}$ & $\begin{array}{r}387 \mathrm{~nm} \\
407 \mathrm{~nm} \\
532 \mathrm{~nm} \\
0.1-5 \text { (Raman) } \\
6-40 \text { (elastic) }\end{array}$ & $\begin{array}{r}\text { Newtonian } \\
150 \mathrm{~mm}, \mathrm{~F} 3 \\
1.8 \\
\text { yes }\end{array}$ \\
\hline $\begin{array}{l}\text { Time resolution }(\mathrm{sec}) \\
\text { Vertical resolution }(\mathrm{m})\end{array}$ & $\begin{array}{l}60 \\
75\end{array}$ & $\begin{array}{l}60 \\
75\end{array}$ & $\begin{array}{l}60 \\
75\end{array}$ \\
\hline
\end{tabular}

The dashed horizontal lines indicate the inflection points corresponding to the cirrus boundaries.

Due to the scale of the structures observed (at least some hundreds of meters), the value of $375 \mathrm{~m}$ ( 5 lidar points) has been fixed for the width of the wavelet, having verified that the variation of this parameter (from 225 to $975 \mathrm{~m}$ ) does not significantly affect the identification of boundaries.

The presence of a cirrus is revealed when the absolute values of $W_{\mathrm{B}}(a, b, z)$ exceed a fixed threshold $\left(W_{\mathrm{s}}\right)$ and the temperature is below $-25^{\circ} \mathrm{C}$. The value of $W_{\mathrm{s}}$ has been chosen through a study of sensitivity that considered the signal to noise ratio (SNR) of the SR profile. The employment DWT technique, being based on an integral quantity instead of a derivative, it is much less prone to noise-induced detections than a numerical differentiation technique based on the direct analysis of SR, which, in upper troposphere and in the case of strong extinguishing cirrus, is often subjected to low values of SNR.

The effective height $\left(z_{\text {cir }}\right)$ is defined per Chen at al. (2002):

$$
z_{\text {cir }}=\frac{\int_{\text {base }}^{z_{\text {top }}} z^{\prime} \cdot \operatorname{SR}\left(z^{\prime}\right) \mathrm{d} z^{\prime}}{\left.\int_{z_{\text {base }}}^{z_{\text {top }}} \operatorname{SR}\left(z^{\prime}\right) \mathrm{d} z^{\prime}\right)},
$$

namely the SR mass center of the cirrus.

Optical depth $(\tau)$ has been estimated using the SR profile inside the cirrus with a fixed a priori value of lidar ratio (LR,
Goldfarb et al., 2001):

$\tau_{\text {cir }}=\mathrm{LR} \cdot \frac{\mathrm{d} \sigma_{\text {Ray }}}{\mathrm{d} \Omega} \int_{Z_{\text {base }}}^{z_{\text {top }}} n_{\text {air }}(z) \cdot(\operatorname{SR}(z)-1) \mathrm{d} z$

where $\mathrm{d} \sigma_{\text {Ray }} \mathrm{d} \Omega^{-1}=5.7 \cdot 10^{-32} \mathrm{~m}^{2} \mathrm{sr}^{-1}$ is the backscattering differential molecular cross section, $n_{\text {air }}$ is the molecular density derived by radiosonde measurements, and LR $=18.2 \mathrm{sr}$ (Platt and Diley, 1984). The value of LR will be discussed in Sect. 3.2. Even though one of the advantages of this particle integration (PI) method is a low sensitivity to SNR (Cadet et al., 2005), it should be stressed that LR strictly depends on the ice crystal optical properties and the employment of an a priori value of LR (i.e., assumption of fixed physical properties), which could introduce some errors on the derived values. Furthermore, due to the vertical pointing of the RMR laser, also the specular reflection effect could affect the value of $\tau_{\mathrm{LR}}$.

The evaluation of $\tau$ has been performed also using the extinction of Raman signal below and above the cirrus (Raman method, Ansmann et al., 1992):

$\tau_{\mathrm{Rm}}=-\frac{1}{2 \eta} \cdot \ln \left(\frac{S_{\mathrm{N} \_c a l}\left[z_{\text {top }}: z_{2}\right]}{S_{\mathrm{N} \_ \text {cal }}\left[z_{1}: z_{\text {base }}\right]}\right)$,

where $S_{\mathrm{N} \text { cal }}$ is the Raman nitrogen signal calibrated with the radiosonde profile in the atmospheric layers below $\left(z_{1}: z_{\text {base }}\right)$ and above $\left(z_{\text {top }}: z_{2}\right)$ the cirrus (where $z_{\text {base }}-z_{1}$ and $z_{2}-z_{\text {top }}$ are equal to 500 and $800 \mathrm{~m}$, respectively), corrected from the 
molecular extinction and assuming negligible aerosol background, and $\eta$ is the corrective factor that takes into account the multiple scattering (MS) effect. Using only a single lidar signal, the Raman method could be significantly influenced by MS (Wandinger, 1998). This effect depends on several factors (laser divergence, field of view of the receiver, laser penetration depth, cloud height, particle size distribution, and crystal shapes). Following Seifert et al. (2007), a MS factor $\eta=0.60 \pm 0.1$ for cirrus geometrical depths $<1 \mathrm{~km}$ and $\eta=0.7 \pm 0.1$ for larger geometrical depths has been adopted in this analysis. The applicability of the Raman method is limited by the uncertainty due to the weak Raman signal intensity (three orders of magnitude less than elastic backscattered signal).

To reduce the statistical error and obtain reasonable SNR values in the upper troposphere, a temporal integration is performed on the lidar signal before calculating the estimation of the cirrus parameters listed above. The approach adopted consists in analyzing the time series of the optical depth (estimated with PI method) of the mid- and upper troposphere (between 7 and 12/13 km, approximately) with a temporal resolution of the original raw data to research discontinuity points in order to define quasi-stationary temporal periods (QSTP) regarding statistical variability (Lanzante, 1996). As proposed by Hoareau et al. (2009), data analyses are then performed on these integrated periods to derive accurate optical cirrus properties. To obtain consistent results, this approach should be applied to a statistically meaningful number of points, thus only temporal periods greater than $15 \mathrm{~min}$ (15 points) are considered. The employment of this analysis has also permitted us to homogenize lidar data sets, applying clustering analysis to the same sample. In this work, 93 nighttime lidar sessions acquired between February 2007 and April 2010 have been analyzed through this procedure and 167 cirrus cases have been identified. The QSTP methodology guarantees that the revealed cirrus clouds are independent in terms of statistical variability.

High-resolution radiosonde data (Vaisala RS92) were used from the Italian Meteorological Service in Pratica di Mare ( $25 \mathrm{~km}$ southwest of Rome Tor Vergata) to add complementary description of the background conditions (e.g., density, mid-cirrus height temperature) to the lidar results. The height of the tropopause has been estimated using the definition of thermal tropopause (WMO/World Meteorological Organization, 1957).

\subsection{Multivariate clustering analysis}

Once principal parameters of cirrus quasi-stationary periods are retrieved, different statistical methods could be used to identify cirrus classes. An analysis in terms of probability distribution function (PDF), which revealed non-Gaussian multimode distributions, has been made first. However, as shown by Keckhut et al. (2006), this analysis is not adequate to objectively determine cirrus classes because cross corre- lation between each parameter has to be taken into account. Instead, multivariate analysis (MA) is the better candidate to discriminate the presence of cirrus classes. Thus, a multivariate approach that has already applied to the OHP cirrus data set (Keckhut et al., 2006) and, recently, to subtropical cirrus clouds from the Reunion Island lidar data set (Hoareau et al., 2012) has been employed to analyze the cirrus observations sampled by RTV lidar and radiosonde. A detailed description of this methodology is reported in Borchi and Marenco (2002), while here only the main characteristics of the adopted procedure are discussed.

The adopted MA consists in successively applying, in this order, principal component analysis (PCA), hierarchical clustering method (HCM) and discriminant factor analysis (DFA) to the RTV lidar data set.

The first step is using PCA to reduce data by finding the linear combinations of the original variables, accounting as much as possible for the total variance of the original data (Jolliffe, 1986). Through this analysis, new uncorrelated variables (principal components) are defined and used as parameters describing the observations in the next stage of the MA algorithm that is HCM. The aim of HCM is to group observations into clusters, organized based on growing distances, and aggregating them hierarchically. This method uses Euclidean distance as the dissimilarity measure between observations and the Ward's method (Ward, 1963) for the agglomerative clustering method. The principle is that each observation in a cluster should be as close as possible to other observations in that cluster and, conversely, as far as possible from observations belonging to other clusters. In HCM the number of clusters is supplied a priori. For these reasons, several tests were performed with different numbers of clusters and the final number of classes was selected choosing the most significant discriminative partition regarding the dendrogram of HCM (i.e., the level where there is a significant change of the aggregation index, based on the intra-classes variance using the Ward distance metric).

Lastly, DFA is used after HCM to validate and optimize the clustering and to estimate the discrimination power of each variable, ensuring the robustness of these results. In fact, this analysis, applied on already-classified data, identifies the optimal set of orthogonal projection axes that best discriminate the classes, minimizing the probability of misclassification. DFA produces a number of functions useful for discriminating among clusters of data obtained by HCM. Data membership probabilities to clusters can be calculated by those functions allowing data to be reclassified after DFA.

\section{Results}

\subsection{Cirrus classification}

Cirrus clouds have been detected in $47 \%$ of the 93 analyzed lidar sessions (daily occurrence, which is the number 
Table 2. Characteristics of cirrus data set for the period 2007-2010.

\begin{tabular}{lrrrr}
\hline & $\begin{array}{r}\text { Lidar } \\
\text { sessions }\end{array}$ & $\begin{array}{r}\text { Daily and absolute } \\
\text { cirrus occurrence }\end{array}$ & $\begin{array}{r}\text { Cirrus } \\
\text { clouds }\end{array}$ & $\begin{array}{r}\text { Cirrus } \\
\text { multilayer }\end{array}$ \\
\hline $\begin{array}{l}\text { RMR dataset } \\
(2007-2010)\end{array}$ & 93 & $47-30 \%$ & 167 & 29 \\
\hline
\end{tabular}

of cirrus detections divided by the total number of measurements), whereas the absolute occurrence is $30 \%$ (i.e., the ratio of cirrus detection time on the total lidar measurement time). Before discussing statistical details, it is important to specify that nighttime lidar measurements were performed only in the absence of precipitation and for lower tropospheric (below $4 \mathrm{~km}$ ) thick extinguishing clouds. However, Dupont et al. (2010) have shown with CALIOP (CloudAerosol Lidar with Orthogonal Polarization) data that neither nighttime nor ground conditions introduced any obvious bias in cirrus climatology using ground-based lidar at midlatitudes. It is also noteworthy that for $17 \%$ of cirrus cases, multilayer cirrus have been observed and analyzed separately when more than $500 \mathrm{~m}$ of clear air appeared between them. Table 2 summarizes the data set analyzed through the multivariate clustering.

The cirrus parameters of the 167 QSTP, processed by the MA approach, are mid-cirrus height, geometrical depth, midcirrus height temperature, SR mean intensity, and relative height (the difference between cirrus top height and thermal tropopause). These parameters have been chosen following Keckhut et al. (2006). In particular, since the required assumptions on the estimation of the cirrus $\tau$ (e.g., effects of multiple scattering, weakness of the signal in the case of the Raman method and a priori and fixed value of LR in the case of PI method) produce a larger uncertainty compared to the other parameters, this variable has not been considered at this stage. However, it has been verified that the use of $\tau$ as one of the five parameters led to the same results in terms of cirrus classes, most probably because $\tau$ is not independent from the measured parameters such as geometrical depth and SR.

The three first principal components (PCs) identified by PCA take into account almost the entire $98 \%$ of the cumulative variance, in particular PC1 and PC2 representing $89 \%$ (52 and $37 \%$, respectively). The results obtained by MA are summarized in Fig. 3, where the observations are projected on two orthogonal discriminating axes F1 and F2, obtained by the DFA. Different colors highlight the presence of several clusters, identified by HCM and confirmed by DFA. These clusters correspond to five different cirrus classes, whose main characteristics are reported in Table 3 where the mean and standard deviation for all parameters are listed.

Classes I and III, which refer to thin cirrus observed in mid- and upper troposphere, respectively, are characterized by low values of SR mean intensity, geometrical and optical depth. In contrast, IIa and IIb represent thick cirrus, sensed between 9 and $10 \mathrm{~km}$, with larger vertical extension and higher values of SR and optical depth.

Another characteristic that distinguishes thick from thin cirrus classes is the frequency of occurrence, which is lower for thin cirrus both in mid- and in upper troposphere. The very rare occurrence of the last class (IV), characterized by very high values of the mean backscattering term that could be caused by specular reflection effects, cannot be assessed as this class is considered a distinct class and therefore will not be further discussed in this work.

The bottom part of Table 3 reports the results of the same analysis performed using OHP data set for more than ten years of lidar measurements (Hoareau et al., 2013). The comparison between the French and Italian cirrus classification points out the high similarities for the two classes of thin cirrus identified on both sites (class I and class III, respectively). In fact, for the two classes, the values of mean height and geometrical thickness are in very good agreement.

In contrast to OHP results, the RTV classification seems to split thick cirrus cloud OHP class (II) at $9.8 \mathrm{~km}$ into two distinct classes (IIa anb IIb) located at 8.8 and $10.2 \mathrm{~km}$, respectively. However, combining the values of mean height and geometrical thickness of these two classes, weighted by their occurrence, it is possible to obtain a class with the values of mean height and thickness (9.6 and $3.4 \mathrm{~km}$, respectively) that is closer to class II observed at OHP.

The absolute occurrence of the classes between the two sites are also different: at RTV site, thick cirrus (class IIa and IIb) occurs $15 \%$ of the time (11\% at the OHP), thin tropopause cirrus (class III) are observed only $9 \%(15 \%$ at OHP), and also mid-tropospheric thin cirrus (class I) are less present over the RTV (5\% vs. $10 \%$ ).

\subsection{Cirrus optical properties and attribution}

\subsubsection{Lidar ratio analysis}

The optical properties of each cirrus class have been studied through the combined use of elastic and Raman nitrogen lidar channels. In particular, to have an homogenous data set, the values of the effective $L R$ ( $L R_{\text {eff }}$, the ratio between the extinction and the integrated value of SR inside the cirrus) have been estimated only for cirrus cases with $\Delta \tau_{\mathrm{Rm}} / \tau_{\mathrm{Rm}} \leq 30 \%$, where $\Delta \tau_{\mathrm{Rm}}$, the error associated to $\tau_{\mathrm{Rm}}$, is calculated applying the propagation error formula to Eq. (7) (considering the signal random errors). Only 107 cirrus cases ( $65 \%$ of the total 167) have been considered. The number of cirrus cases analyzed, the values of the mean for $\tau_{\mathrm{LR}}, \tau_{\mathrm{Rm}}, \mathrm{LR}_{\mathrm{eff}}$, the root mean square (RMS) of the errors associated to $L_{\text {eff }}$ values $\left(\Delta \mathrm{LR}_{\mathrm{eff}}\right)$, together with the relative position of SR mass center compared to the mean geometric height, are listed for each class in Table 4.

For the subsample, the $\tau_{\mathrm{LR}}$ mean values for each class are higher than those computed for the entire sample. This is consistent because small values of optical depth are, 
Table 3. Principal lidar parameters of the cirrus classes identified by multivariate analysis applied to the RTV data set (2007-2010). Temperature values are derived from the operational radiosonde launched from Pratica di Mare (25 km southwest of RTV). In the bottom part of the table, the lidar parameters of the cirrus classes identified at OHP by the same analysis are listed.

\begin{tabular}{|c|c|c|c|c|c|}
\hline RTV & $\begin{array}{l}\text { I: Mid-tropo. } \\
\text { thin cirrus }\end{array}$ & $\begin{array}{l}\text { IIa: Upper } \\
\text { tropo. cirrus }\end{array}$ & $\begin{array}{l}\text { IIb: Upper } \\
\text { tropo. cirrus }\end{array}$ & $\begin{array}{l}\text { III: Thin } \\
\text { tropopause cirrus }\end{array}$ & $\begin{array}{l}\text { IV: Episodic highly } \\
\text { scattering cirrus }\end{array}$ \\
\hline Relative occurrence [\%] & 17 & 30 & 21 & 30 & 2 \\
\hline Absolute occurrence [\%] & 5 & 9 & 6 & 9 & $<1$ \\
\hline Geometric height [km] & $7.8 \pm 0.9$ & $10.2 \pm 0.9$ & $8.8 \pm 0.9$ & $11.2 \pm 0.7$ & $10.9 \pm 1.6$ \\
\hline Thickness $[\mathrm{km}]$ & $1.2 \pm 0.7$ & $2.8 \pm 0.6$ & $4.3 \pm 0.8$ & $1.3 \pm 0.5$ & $3.1 \pm 0.5$ \\
\hline Intensity of the mean SR & $3.4 \pm 2.3$ & $10.0 \pm 6.4$ & $15.4 \pm 8.1$ & $6.3 \pm 6.3$ & $64.9 \pm 14.8$ \\
\hline Midcloud temperature $\left[{ }^{\circ} \mathrm{C}\right]$ & $-36 \pm 7$ & $-53 \pm 4$ & $-42 \pm 7$ & $-58 \pm 4$ & $-53 \pm 11$ \\
\hline Optical depth (a priori LR) & $0.04 \pm 0.06$ & $0.16 \pm 0.20$ & $0.47 \pm 0.36$ & $0.09 \pm 0.09$ & $1.62 \pm 1.09$ \\
\hline $\mathrm{OHP}$ & $\begin{array}{l}\text { I: Mid-tropo. } \\
\text { thin cirrus }\end{array}$ & \multicolumn{2}{|c|}{$\begin{array}{l}\text { II: Upper } \\
\text { tropo. cirrus }\end{array}$} & $\begin{array}{l}\text { III: Thin } \\
\text { tropopause cirrus }\end{array}$ & $\begin{array}{l}\text { IV: Episodic highly } \\
\text { scattering cirrus }\end{array}$ \\
\hline Absolute occurrence [\%] & 10 & \multicolumn{2}{|c|}{11} & 15 & $<1$ \\
\hline Geometric height $[\mathrm{km}]$ & $8.6 \pm 0.9$ & \multicolumn{2}{|c|}{$9.8 \pm 0.7$} & $11.5 \pm 0.9$ & $10.6 \pm 0.3$ \\
\hline Thickness $[\mathrm{km}]$ & $0.9 \pm 0.6$ & \multicolumn{2}{|c|}{$3.2 \pm 0.9$} & $0.9 \pm 0.6$ & $1.0 \pm 0.8$ \\
\hline
\end{tabular}

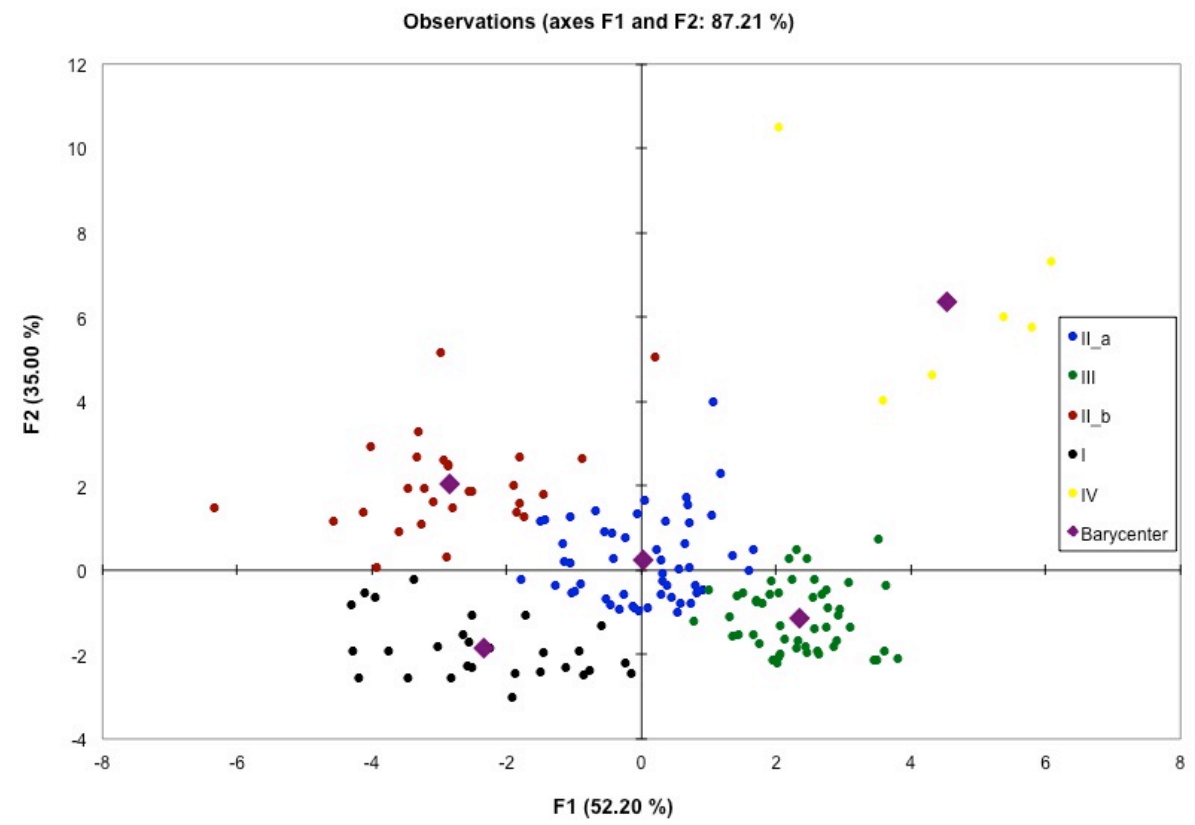

Fig. 3. Cirrus parameters represented (projected) on the two sets of orthogonal axes identified by the DFA, which describe the $87.21 \%$ of the cirrus characteristics. Colored dots identify the different classes discriminated by HCM, while the violet diamonds represent the barycenter of each class.

generally, more affected by the statistical error and therefore discarded. The estimated $\tau_{\mathrm{Rm}}$ is higher in comparison to $\tau_{\mathrm{LR}}$ for all the classes. This result seems to indicate that the used $\mathrm{LR}_{\mathrm{ap}}$ is not adequate to describe the mean cirrus optical properties and a higher value should be employed. In particular, the values of $\mathrm{LR}_{\mathrm{eff}}$ for thick and thin cirrus classes are very similar (31-32 and 28-29 sr, respectively). Figure 4 depicts the frequency distribution functions of $L_{\text {eff }}$ calculated for the four classes. To take into account the variability intro- duced by $\Delta \mathrm{LR}_{\mathrm{eff}}$, these distributions are fitted with Gaussian functions (black curves in Fig. 4) with the expected value $\mu$ equal to the mean of $\mathrm{LR}_{\mathrm{eff}}$ and the variance $\sigma^{2}$ equal to the square of the RMS of $\Delta \mathrm{LR}_{\mathrm{eff}}$.

Classes IIa, IIb and III have the distribution centered between 20 and $40 \mathrm{sr}\left(76 \%, 74 \%\right.$ and $73 \%$ of the $\mathrm{LR}_{\text {eff }}$ are included in this range, respectively), with the latter differing from the two former classes for a less peaked shape. This 
Table 4. Mean optical parameters for each cirrus class derived for a subsample of cirrus cases with $\Delta \tau_{\mathrm{Rm}} / \tau_{\mathrm{Rm}} \leq 30 \%$. The fractions of the total lidar observations used for these results are given in parentheses.

\begin{tabular}{lrrrr}
\hline Class type & $\begin{array}{r}\text { I: Mid-tropo. } \\
\text { thin cirrus }\end{array}$ & $\begin{array}{r}\text { IIa: Upper } \\
\text { tropo. cirrus }\end{array}$ & $\begin{array}{r}\text { IIb: Upper } \\
\text { tropo. cirrus }\end{array}$ & $\begin{array}{r}\text { III: Thin } \\
\text { tropopause cirrus }\end{array}$ \\
\hline Cirrus cases analyzed & $18(60 \%)$ & $34(70 \%)$ & $30(82 \%)$ & $25(47 \%)$ \\
Optical depth (a priori LR) & $0.08 \pm 0.07$ & $0.21 \pm 0.19$ & $0.46 \pm 0.31$ & $0.15 \pm 0.07$ \\
Optical depth (Raman) & $0.10 \pm 0.08$ & $0.31 \pm 0.31$ & $0.75 \pm 0.47$ & $0.21 \pm 0.10$ \\
LR $_{\text {eff }}$ [sr] & $28 \pm 14$ & $31 \pm 10$ & $32 \pm 9$ & $29 \pm 18$ \\
RMS $\left(\Delta\right.$ LR eff $_{\text {en }}$ [sr] & 13 & 9 & 7 & 11 \\
SR mass center relative position & $0.50 \pm 0.07$ & $0.52 \pm 0.08$ & $0.51 \pm 0.09$ & $0.56 \pm 0.06$ \\
\hline
\end{tabular}
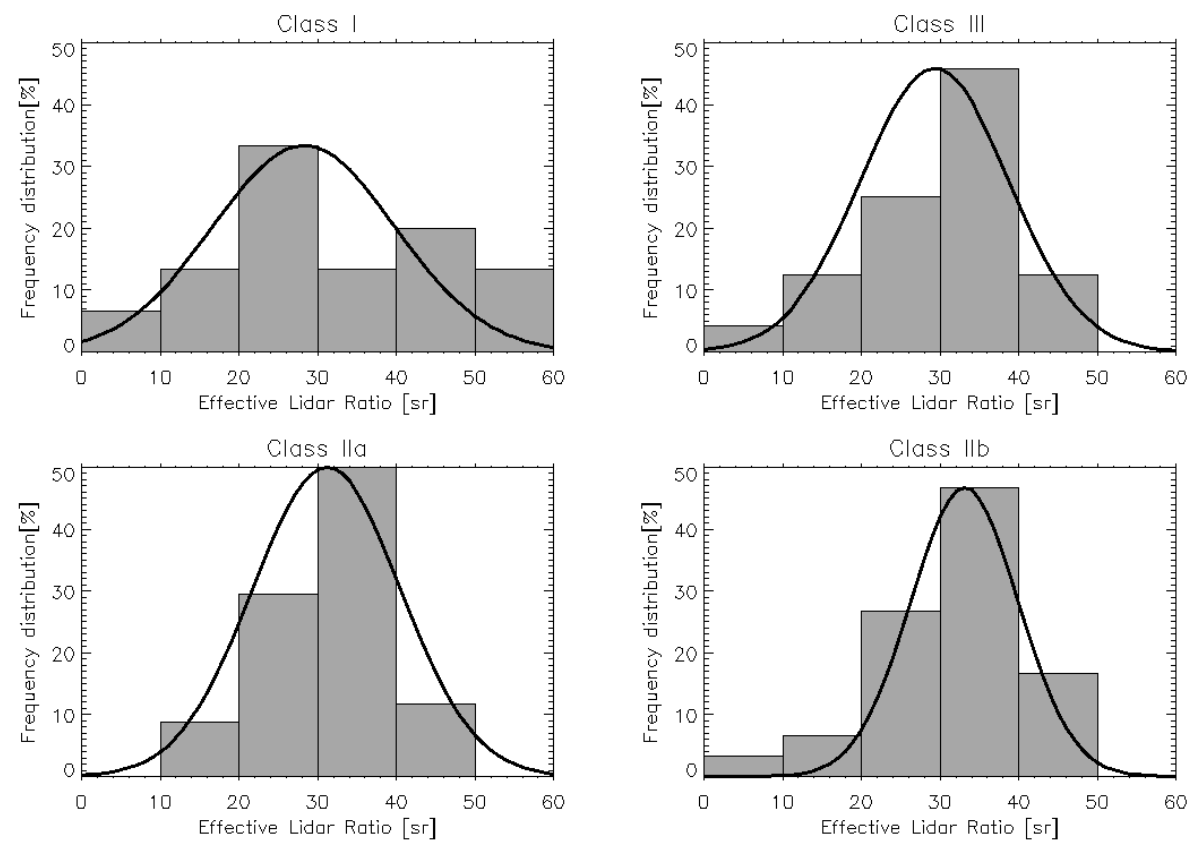

Fig. 4. Frequency distribution functions of $L_{\mathrm{eff}}$ computed for the four cirrus classes fitted with Gaussian functions (black curves), which are determined by the mean of $\mathrm{LR}_{\mathrm{eff}}$ and the root mean square of $\Delta \mathrm{LR}_{\mathrm{eff}}$.

characteristic is stressed in class I, which presents a more flattened shape.

The comparison between the spread of the $\mathrm{LR}_{\text {eff }}$ distributions and of the superimposed Gaussian functions highlights that the distribution variability of $\mathrm{LR}_{\mathrm{eff}}$ is due to the lidar random noise. In particular, this effect is more visible for cirrus class I, which is characterized by larger errors (smaller values of $\tau_{\mathrm{Rm}}$, and then of $L R_{\text {eff }}$, are more affected by the signal fluctuations due to the statistical error noise than larger values of $\tau_{\mathrm{Rm}}$ ).

Figure 5 presents the $\mathrm{LR}_{\mathrm{eff}}$ values as a function of midcloud temperature $\left(T_{\mathrm{mc}}\right)$ for class I (first row) and class III (second row) in terms of a scatter plot (first column, where the $L_{\text {eff }}$ with the associated uncertainties are plotted for function of $\mathrm{T}_{\mathrm{mc}}$ ) and of frequency distribution representation (second column, where the $\mathrm{LR}_{\mathrm{eff}}$ values, weighted with their uncertainties, are depicted with respect to midcloud temper- ature intervals of $5 \mathrm{~K}$ ). The tropopause thin cirrus class is characterized by a small temperature interval (only $10 \mathrm{~K}$ ) and a not significative dependence between $\mathrm{LR}_{\mathrm{eff}}$ and $T_{\mathrm{mc}}$. On the contrary, although the amplitude of the error bars is not negligible, the mid-tropospheric thin cirrus class exhibits a larger temperature interval $(20 \mathrm{~K})$ and trend of $\mathrm{LR}_{\mathrm{eff}}$ increasing from approximately 10 to 45 sr with temperature decreasing between -25 and $-40^{\circ} \mathrm{C}$.

Whiteman et al. (2004) measured a similar dependence in this temperature range for non-hurricane cirrus cases whose origins were attributed to local sources. Since also supercooled water clouds could form between -25 and $-40{ }^{\circ} \mathrm{C}$, it is not possible, at this stage, to resolve the ambiguity regarding this class. Similarly, we cannot exclude that low values of $\operatorname{LR}_{\text {eff }}(\sim 10)$ in the lower left panel of Fig. 5 could be due to the presence of oriented plates. 

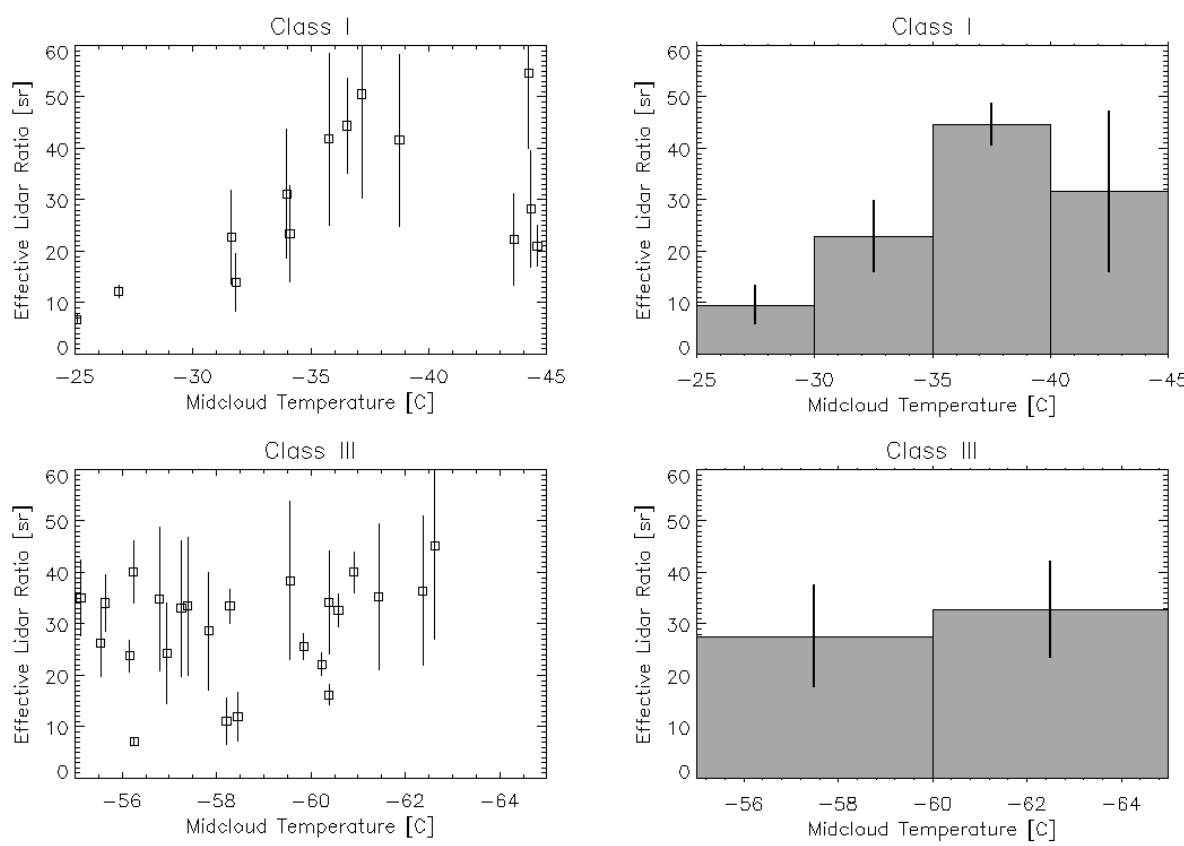

Fig. 5. Effective LR as function of midcloud temperature for classes I and III (first and second rows, respectively). In the first column, single LR values together with their uncertainties (black vertical lines) are plotted with respect to midcloud temperature, while the second column represents the frequency distributions of LR-weighted means with respect to midcloud temperature intervals of $5 \mathrm{~K}$. The black vertical lines are the uncertainties of the single values and the standard deviations of the weighted means (first and second columns, respectively).

The same analysis of $\mathrm{LR}_{\mathrm{eff}}$ in function of $T_{\mathrm{mc}}$ for thick cirrus is depicted in Fig. 6 (first and second rows for classes IIa and IIb, respectively). The two classes show different dependencies. In particular, for class IIa, the $\mathrm{LR}_{\text {eff values }}$ slightly decrease with temperature lowering from -45 to $-60^{\circ} \mathrm{C}$, while an opposite trend characterizes the class $\mathrm{IIb}$ from -30 to $-50^{\circ} \mathrm{C}$. The different temperatures, at which the two classes are observed, could explain these behaviors. However the amplitude of the standard deviation of the frequency distribution of $\mathrm{LR}_{\text {eff }}$ weighted means (black vertical lines in the second column of Fig. 6) reduce the statistical significance of the retrieved results and do not permit to deduce any evident trends for these cirrus classes. Furthermore, MS could also affect the $\mathrm{LR}_{\text {eff }}$ trends. In fact, although these effects have been considered using a single value correction (see Sect. 2.2), the employment of two different lidar channels (with different fields of view and wavelengths) to retrieve $L_{\text {eff }}$ could introduce another source of uncertainty on the $\mathrm{LR}_{\text {eff }}$ variability.

It is to be noted that, for the four classes, the dependence of $L_{\text {eff }}$ on optical depth and effective height was also analyzed (not reported here), but no clear and significant tendencies were found.

\subsubsection{Cirrus class and meteorological parameters}

Since the $\mathrm{LR}_{\text {eff }}$ analysis is limited by the random noise lidar error and by the uncertainty of multiple scattering effects, a preliminary analysis of some meteorological parameters have been performed to characterize cirrus classes.

One of the main applications of the RMR lidar is to provide atmospheric WV measurements in the whole troposphere (Congeduti et al., 1999); recently, a semi-automatic parametric calibration procedure (Dionisi et al., 2010) allowed calibrating the entire data set (2003-2011). Thus, deriving the WV mixing ratio from the Raman signals acquired together with the cirrus elastic channel and the temperatures from Pratica di Mare radiosonde, it has been possible to estimate the mean relative humidity over ice (RHi) for class I. The retrieved value $(\mathrm{RHi}=110 \pm 30 \%)$ is consistent with those estimated by Immler et al. (2008) inside subvisible (SVC) and contrails clouds at Lindenberg (Germany) and, in general, to those measured in the Northern Hemisphere (NH) during the INCA (Interhemispheric Differences in Cirrus Properties From Anthropogenic Emissions) experiment (Ström et al., 2003). It has to be noted that this value was obtained assuming that, although the sites are not collocated, the temperature measured by the radiosonde is representative also for the cirrus above the lidar site.

The value of calculated RHi, together with the high value of cirrus mid-height temperature for this class $\left(\approx-37^{\circ} \mathrm{C}\right)$, could indicate heterogeneous ice formation (Hagg et al., 2003). In our case, a local source known to trigger the cirrus formation could be ascribed to the aircraft exhaust. The lower value of $\mathrm{LR}_{\mathrm{eff}}$ for class I could be associated to the 

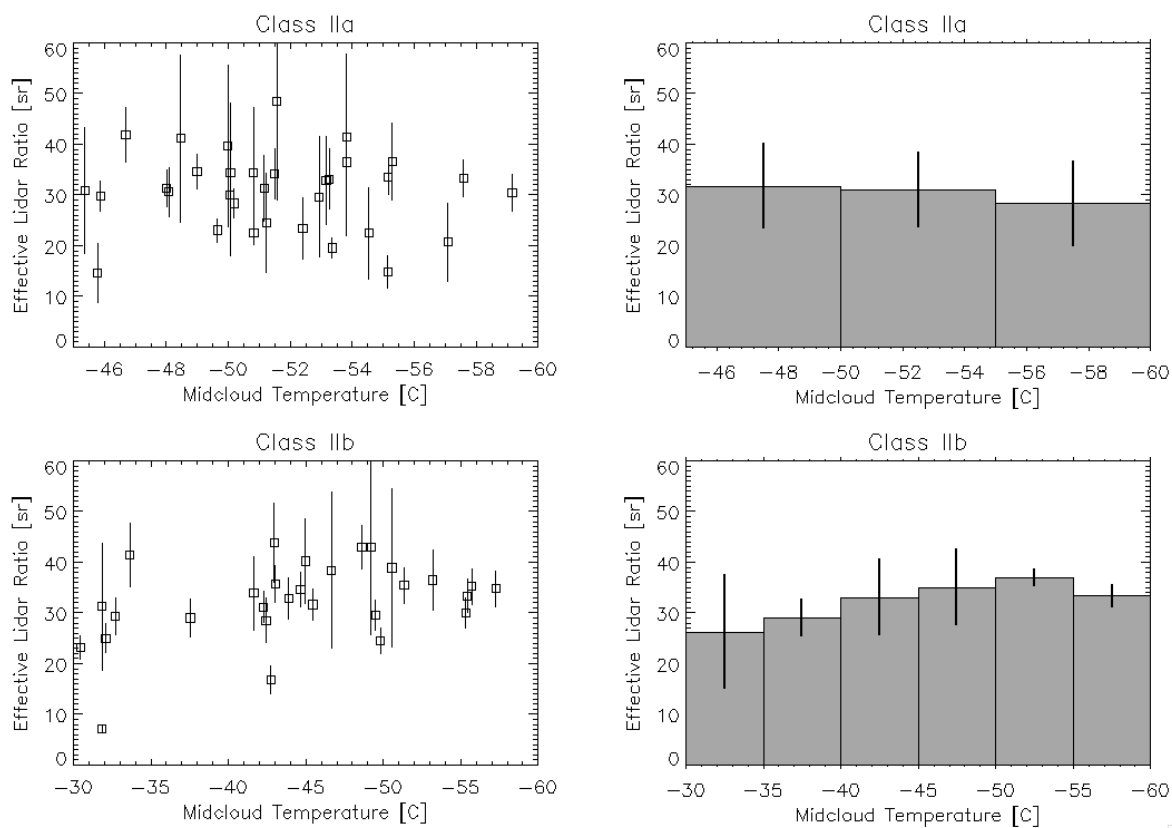

Fig. 6. Effective LR as function of midcloud temperature for classes IIa and IIb (first and second rows, respectively). In the first column, single LR values together with their uncertainties (black vertical lines) are plotted with respect to midcloud temperature, while the second column represents the frequency distributions of LR-weighted means with respect to midcloud temperature intervals of $5 \mathrm{~K}$. The black vertical lines are the uncertainties of the single values and the standard deviations of the weighted means (first and second columns, respectively).

formation of a large amount of small crystals due to the injection of WV by the aircraft engines.

For the other classes a reliable estimation of RHi has not been possible due to the weakness of the WV Raman signal at higher altitudes, which causes a relative uncertainty of more than $60 \%$, and the wet bias effect (approximately between 10-20 ppm) affecting the measurements above $10 \mathrm{~km}$.

Radiosonde data from Pratica di Mare WMO station (no. 16245) have been used to verify if there are some evident relationships between the identified cirrus classes and meteorological parameters other than temperature. In Fig. 7 the mean profiles of $\mathrm{RH}$, of the zonal $(U)$ and of the meridional $(V)$ components of the wind are depicted (panels a, b and c) for each class (black, blue, red, and green curves for classes I, IIa, IIb and III, respectively) in functions of the relative height regarding the cirrus lower boundary $\left(\mathrm{DZ}=z-z_{\text {bot }}\right.$, where $z_{\text {bot }}$ is the cirrus bottom).

The analysis of RH in functions of DZ (plot a) draws attention to the class III (green line), as the one with a well defined humid layer surrounding the cirrus (from approximately -1000 to $1000 \mathrm{~m}$ ), in contrast with class IIa (blue line), which has an almost constant RH behavior along the whole considered atmospheric layer. Class I has a RH gradient in the vertical region just below the cirrus, while the class $\mathrm{IIb}$ is characterized by a strong RH gradient that crosses inside the cirrus. It is worth noting that the RH values were not corrected by the dry bias that affects the RS92 sensor in upper troposphere (Miloshevich et al., 2009).
Although from plot $\mathrm{c}$ of Fig. 7 each class seems to be characterized by a different value of the meridional wind component, these differences, as well as those of the zonal wind component (Fig. 7, plot b), are less significant.

\subsubsection{Midlatitude cirrus comparison}

To compare and evaluate the cirrus optical parameters in Table 4 with lidar measurements at similar latitudes, these parameters have been recomputed following the classification scheme of Sassen and Cho (1992). The obtained results are presented in Table 5. The observed relative occurrences for the three classes $(10 \%, 49 \%, 41 \%)$ are comparable to other midlatitude measurements taken above central Europe (Reichardt et a., 1999, 10\%, $60 \%$ and $30 \%$ ), over Greece (Giannakaki et al., 2007, 3\%, $57 \%$ and 40\%), and Oklahoma (Wang and Sassen, 2002, 10\%, 65\% and 25\%) but differ from those above Utah (Sassen and Campbell, 2001, 10\%, $30 \%, 60 \%$ ). A maximum occurrence for thin cirrus was also found by Goldfarb et al. (2001) above southern France and by Immler and Schrems (2002) for northern and southern midlatitude sites (Prestwick (Pr) and Punta Arenas (PA)), while more SVC cirrus cases were measured (approximately $20 \%$ ). The estimated values of $\mathrm{LR}_{\text {eff }}\left(26,29\right.$ and $32 \mathrm{sr}$ for $\tau_{\mathrm{Rm}}$ equal to $0.03,0.17$ and 0.69 , respectively) for the three classes highlight an increasing trend of the lidar ratio with the rise of the cirrus optical depth. This tendency is in contradiction with the observations of the cirrus lidar ratio over Utah 

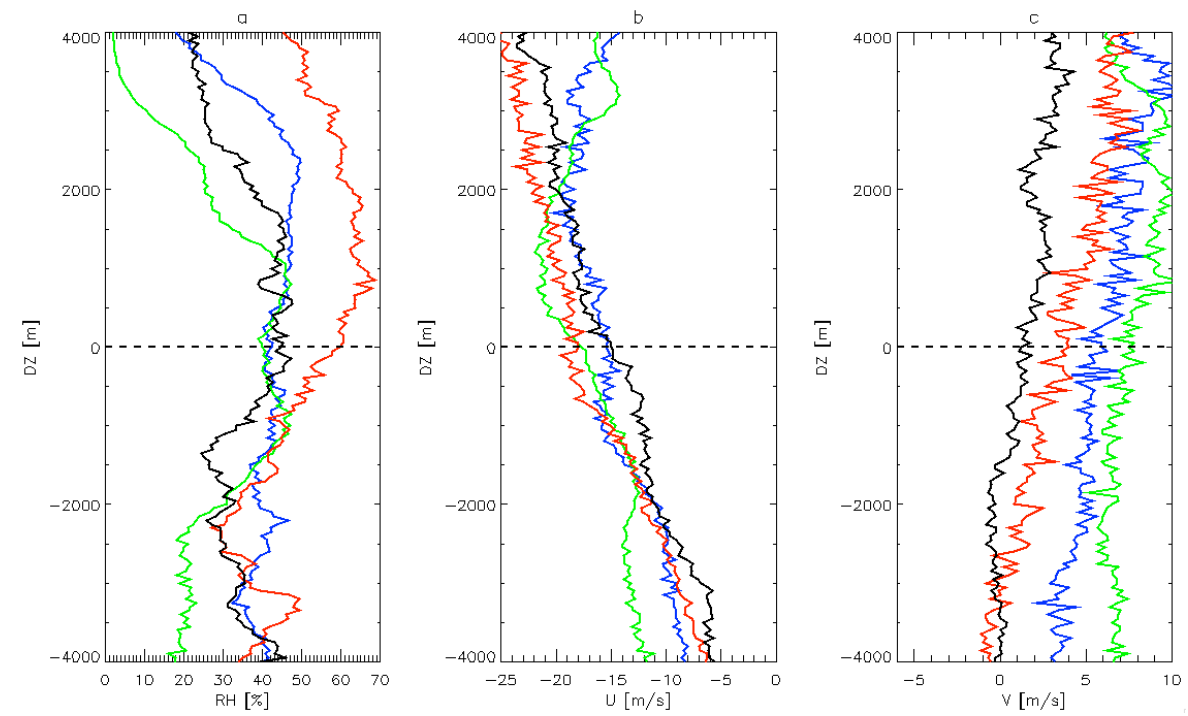

Fig. 7. Mean profiles of relative humidity $(\mathrm{RH})$, zonal $(U)$ and meridional $(V)$ wind components (plot a, b and c, respectively) as function of the relative height regarding the cirrus lower boundary (horizontal dashed black line). Colored curves represent the different cirrus classes (black, blue, red, and green curves for classes I, IIa, IIb and III, respectively).

(Sassen and Comstock, 2001), where values of about 35, 27, 22,22 , and $21 \mathrm{sr}$ were measured for optical depths around $0.12,0.25,0.5,1,1.2$, and 2.5 , respectively.

The overall mean value of $\tau_{\mathrm{Rm}}(0.37 \pm 0.18)$ is higher than to those derived by other midlatitude cirrus data sets, as Reichardt (1999, $\tau=0.25-0.30)$, Immler and Schrems (2002, $\tau=0.28 \pm 0.11$ for Pr and $\tau=0.27 \pm 0.08$ for PA), Lakkis et al. (2011, $\tau=0.29 \pm 0.09)$, and similar to Giannakaki et al. $(2007, \tau=0.31-0.34)$. Similarly the mean value of $L_{\text {eff }}$ $(31 \pm 15 \mathrm{sr})$ appears higher compared to midlatitude measurements and agrees better with cirrus observed at lower latitudes, as above Taiwan (Chen, 2002, LR $=29 \pm 12 \mathrm{sr}$ ) or over the tropical Indian Ocean during northeast (NE) and southwest (SW) monsoon seasons ( $\mathrm{LR}=33 \pm 9 \mathrm{sr}$ for $\mathrm{NE}$ and $\mathrm{LR}=29 \pm 11 \mathrm{sr}$ for $\mathrm{SW}$ ).

\section{Summary and conclusions}

The data set of RTV lidar, a multichannel instrument (optimized for water vapor measurements), has been, for the first time, employed to characterize cirrus clouds. In particular, using the elastic and the Raman nitrogen channels of the system, cirrus characteristics such as effective height, geometrical and optical thickness and mean back-scattering ratio have been derived. The mid-height temperature inside the cloud, estimated through the radiosonde data of Pratica di Mare, $25 \mathrm{~km}$ southwest from RTV site, was added to integrate the data set.

Defining the cirrus occurrence as the ratio of the number of cirrus detections and the total number of measurements, cirrus clouds were detected in $47 \%$ of the operational days, a value similar to the one ( $45 \%)$ measured by Gobbi et al. (2004) above the same site. However, this percentage lowers to $30 \%$ if the ratio of cirrus detection time for the total measurement time is taken into account. It is noteworthy that these statistics are derived for nighttime measurements acquired in the absence of precipitation and of lower tropospheric clouds.

The characterization of the detected cirrus was performed through a clustering multivariate analysis approach previously adopted for the OHP lidar. This statistical method was applied to the Italian site for the considered period, the RTV cirrus data set for the period February 2007-April 2010 (93 lidar sessions, approximately $500 \mathrm{~h}$ of lidar acquisitions), which resulted in the identification of four cirrus classes above two thin cirrus clusters in the mid- and upper troposphere (class I and III, respectively) and two thick cirrus clusters in the upper troposphere (class IIa and IIb).

The comparison of these results to the ones obtained by OHP analysis attests the validity both of the employment of RTV lidar on cirrus investigation and of the clustering method used. Thin cirrus classes observed above the two sites result in very similar lidar parameters (cirrus effective height, geometrical and optical depth), while the thick cirrus class, identified at the OHP, seems to be split into two subclasses for the RTV site (classes IIa and IIb). The absolute cirrus occurrence is less at the Italian than at the French site $(30 \%$ vs. $37 \%$, respectively) while the occurrence of each cirrus class varies between the lidar stations, highlighting the fact that different weather patterns characterize the two sites.

With the objective of explaining the main physical processes that control these classes, the analysis of the effective lidar ratio of a subsample of cirrus cases (approximately $65 \%$ ) with $\Delta \tau_{\operatorname{Rm}} / \tau_{\mathrm{Rm}} \leq 30 \%$ have been performed. 
Table 5. Frequency, mean optical depth (Raman method), effective lidar ratio (LR) and backscattering mass center relative position for the subsample of cirrus data set discretized following Sassen and Cho (1992) classification scheme.

\begin{tabular}{lrrrr}
\hline Class type & $\begin{array}{r}\text { Subvisible } \\
\text { Cirrus, } \tau<0.03\end{array}$ & $\begin{array}{r}\text { Thin Cirrus } \\
0.03<\tau<0.3\end{array}$ & $\begin{array}{r}\text { Opaque Cirrus } \\
0.3<\tau<3\end{array}$ & All Cirrus \\
\hline Frequency [\%] & 10 & 49 & 41 & - \\
Optical depth (Raman) & $0.026 \pm 0.007$ & $0.17 \pm 0.09$ & $0.69 \pm 0.32$ & $0.37 \pm 0.18$ \\
Effective LR [sr] & $26 \pm 20$ & $29 \pm 15$ & $32 \pm 11$ & $31 \pm 22$ \\
SR mass center relative position & $0.54 \pm 0.05$ & $0.53 \pm 0.08$ & $0.52 \pm 0.10$ & $0.52 \pm 0.10$ \\
\hline
\end{tabular}

Taking into account the associated errors, the frequency distribution functions of $\mathrm{LR}_{\mathrm{eff}}$ values and their dependence on the mid-height cirrus temperature have been studied. The obtained results might attest that thin cirrus classes are composed of crystals smaller and more regular in shape compared to thick classes and that heterogeneous nucleation and a local source, such as aircraft exhaust, could be a possible origin of mid-tropospheric thin cirrus (class I).

However, nonlinear effects of signal noise, oriented plates, multiple scattering effects and supercooled water clouds have a significant impact on these analyses, reducing the confidence of the results.

The preliminary study on meteorological parameters, in which the mean profiles of relative humidity and the wind components have been estimated for each cirrus cluster, validates the fact that different meteorological conditions could be associated with different cirrus classes.

In particular, the retrieved well-defined humid layer surrounding high, thin tropopause cirrus (class III) confirms that the formation of this class is connected to the large-scale transport processes of moist tropical upper tropospheric air masses (Keckhut et al., 2005 and Montoux et al., 2010).

At the latitudes of the RTV site, thick cirrus (classes IIa and IIb) could be associated with midlatitude cirrus preceding weather disturbances, as indicated by the work of Sassen and Comstock (2001), but no significant indications on this were found in the present study. Dedicated studies are needed to further investigate the attribution and origin of cirrus classes I, IIa and IIb.

The comparison of the RTV cirrus results with other lidar cirrus data sets through the classification scheme of Sassen and Cho (1992) are in good agreement with other midlatitude lidar measurements regarding optical depth. In particular, these results confirm previous analyses of cirrus clouds with lidar that show that thin cirrus at midlatitudes are present in a greater percentage $(49 \%)$ than thick or opaque cirrus $(41 \%)$.

For the $\mathrm{LR}_{\mathrm{eff}}$, most retrieved values ranged from $10-60 \mathrm{sr}$, in agreement with other works performed at different latitudes (Sassen and Comstock, 2001; Chen et al., 2002; Whiteman et al., 2004; Seifert et al., 2007) but in contrast with the values estimated by Platt et al. (2002) through the LIRAD (lidar radiometer) technique. The estimated mean value of LR $_{\text {eff }}(31 \pm 15 \mathrm{sr})$ agrees better with LR values of cirrus observed at lower latitudes than those calculated at similar latitudes. The reason for these similarities between cirrus at different latitudes is not known. Furthermore, a large uncertainty exists in the comparison of LR calculated by different systems due to possible different definitions of a single cirrus cloud layer as well as the approach to correct for multiple scattering effects and system setups.

Finally, the comparison between the clustering and the standard cirrus classification (Tables 4 and 5 in Sect. 3.2) shows that SVC cirrus clouds include classes I and III, thin cirrus are mainly formed by classes III and IIa, and opaque cirrus correspond to class IIb and IIa. It is interesting to note that the classical cirrus subdivision does not allow distinguishing between the different heights (and origin) of the different classes, which, as in the case of classes I and III, can cause significant differences in terms of radiative impact. This confirms the fact that a cirrus classification using only optical depth as a discriminating factor is meaningful for practical purposes, but it does not provide any indication of the cirrus generating process.

On the contrary, the consistency of the obtained results suggests that a cirrus classification based on a statistical approach gives more indications on the physical mechanisms that govern these classes, and, consequently, could improve the estimation of the associated LR values, which are important also for the validation and development of the algorithm adopted to calculate cirrus optical depth from space borne lidar such as the Cloud-Aerosol Lidar with Orthogonal Polarization (CALIOP).

For these reasons, further studies with dedicated campaigns are planned to extend this procedure to other locations and to improve the characterization of the optical properties of each class.

Within this framework, similar to the studies conducted on tropical cirrus (Fortuin et al., 2007; Sunilkumar et al., 2010; Das et al., 2011), the next planned step will be to characterize in detail the meteorological condition of several cirrus cases with the objective of relating each class to one or more processes controlling cirrus formation and evolution. The RMR lidar configuration will be improved to increase the WV measurement accuracy in the upper troposphere, reducing the statistical error and correcting the wet bias. This will make it possible to use the spatial and temporal information provided 
by the simultaneous lidar measurements of cirrus clouds and water vapor to investigate the key processes controlling cirrus formation and evolution (e.g., Luo and Rossow, 2004) and to ameliorate the knowledge of the water vapor vertical distribution in the upper troposphere. Furthermore, the recent implementation (August 2013) of the new detection channel at $355 \mathrm{~nm}$ in the RMR lidar system will allow the estimation of the Angstrom coefficient, which, coupled with the lidar ratio parameter, could add useful information about the cirrus crystal particle size and shape, making a significant contribution to the understanding of the cirrus class controlling factors.

Acknowledgements. The research leading to these results has received funding from the European Union Seventh Framework Programme (FP7/2007-2013) and University of Versailles and Saint Quentin en Yvelines (UVSQ) under grant agreement RBUCE-UP no. 246556. Radiosonde data are routinely supplied by the Italian Meteorological Service of the Military Aeronautics.

Edited by: S. Buehler

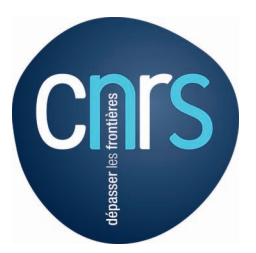

The publication of this article is financed by CNRS-INSU.

\section{References}

Ansmann, A., Wandinger, U., Riebesell, M., Weitkamp, C., and Michaelis, W.: Independent measurement of extinction and backscatter profiles in cirrus clouds by using a combined Raman elastic-backscatter lidar, Appl. Opt., 31, 7113-7113, 1992.

Borchi, F. and Marenco, A.: Discrimination of air masses near the extratropical tropopause by multivariate analyses from MOZAIC data, Atmos. Environ., 36, 1123-1135, 2002.

Brooks, I. M.: Finding boundary layer top: application of a wavelet covariance transform to lidar backscatter profiles, J. Atmos. Ocean. Tech., 20, 1092-1105, 2003.

Cadet, B., Giraud, V., Haeffelin, M., Keckhut, P., Rechou, A., and Baldy, S.: Improved retrievals of the optical properties of cirrus clouds by a combination of lidar methods, Appl. Opt., 44, 17261734, 2005.

Chen, W. N., Chiang, C. W., and Nee, J. W.: Lidar Ratio and Depolarization Ratio for Cirrus Clouds, Appl. Opt., 41, 6470-6476, 2002.

Chepfer, H., Bony, S. D., Winker, M., Chiriaco, M., Dufresne, J. L., and Seze, G.: Use of CALIPSO lidar observations to evaluate the cloudiness simulated by a climate model, Geophys. Res. Lett., 35, L15704, doi:10.1029/2008GL034207, 2008.

Congeduti, F., Marenco, F., Baldetti, P., and Vincenti, E.: The multiple-mirror lidar "9-eyes", J. Opt. A-Pure Appl. Op., 1, 185191, 1999.

Das, S. K., Chiang, C. W., and Nee, J. B.: Influence of tropical easterly jet on upper tropical cirrus: An observational study from CALIPSO, Aura-MLS, and NCEP/NCAR data, J. Geophys. Res., 116, D12204, doi:10.1029/2011JD015923, 2011.

Dionisi, D., Congeduti, F., Liberti, G. L., and Cardillo, F.: Calibration of a Multichannel Water Vapor Raman Lidar through Noncollocated Operational Soundings: Optimization and Characterization of Accuracy and Variability, J. Atmos Ocean. Tech., 27, 108-121, 2010.

Dupont, J. C., Haeffelin, M., Morille, Y., Noël, V., Keckhut, P., Winker, D., Comstock, J., Chervet, P., and Roblin, A.: Macrophysical and optical properties of midlatitude cirrus clouds from four ground-based lidars and collocated CALIOP observations, J. Geophys. Res., 115, D00H24, doi:10.1029/2009JD011943, 2010.

Fortuin, J. P. F., Becker, C. R., Fujiwara, M., Immler, F., Kelder, H. M., Scheele, M. P., Schrems, O., and Verver, G. H. L.: Origin and transport of tropical cirrus clouds observed over Paramaribo, Suriname $\left(5.8^{\circ} \mathrm{N}, 55.2^{\circ} \mathrm{W}\right)$, J. Geophys. Res., 112, D09107, doi:10.1029/2005JD006420, 2007.

Giannakaki, E., Balis, D. S., Amiridis, V., and Kazadzis, S.: Optical and geometrical characteristics of cirrus clouds over a Southern European lidar station, Atmos. Chem. Phys., 7, 5519-5530, doi:10.5194/acp-7-5519-2007, 2007.

Gobbi, G. P., Barnaba, F., and Ammannato, L.: The vertical distribution of aerosols, Saharan dust and cirrus clouds in Rome (Italy) in the year 2001, Atmos. Chem. Phys., 4, 351-359, doi:10.5194/acp-4-351-2004, 2004.

Goldfarb, L., Keckhut, P., Chanin, M. L., and Hauchecorne, A.: Cirrus climatological results from lidar measurements at OHP, Geophys. Res. Lett., 28, 1687-1690, 2001.

Haag, W., Kärcher, B., Ström, J., Minikin, A., Lohmann, U., Ovarlez, J., and Stohl, A.: Freezing thresholds and cirrus cloud formation mechanisms inferred from in situ measurements of relative humidity, Atmos. Chem. Phys., 3, 1791-1806, doi:10.5194/acp3-1791-2003, 2003.

Haij, M. J. D. and Klein Baltink, H.: Continuous mixing layer height determination using the LD-40 ceilometer: a feasibility study KNMI, Scientific Report WR, Koninklijk Nederlands Meteorologisch Instituut, Holland, 2007.

Haladay, T. and Stephens G.: Characteristics of tropical thin cirrus clouds deduced from joint CloudSat and CALIPSO observations, J. Geophys. Res., 114, D00A25, doi:10.1029/2008JD010675, 2009.

Hoareau, C., Keckhut, P., Sarkissian, A., Baray, J. L., and Durry, G.: Methodology for water monitoring in the upper troposphere with Raman lidar at Haute-Provence Observatory, J. Atmos. Ocean. Tech., 26, 2149-2160, 2009.

Hoareau, C., Keckhut, P., Baray, J.-L., Robert, L., Courcoux, Y., Porteneuve, J., Vömel, H., and Morel, B.: A Raman lidar at La Reunion $\left(20.8^{\circ} \mathrm{S}, 55.5^{\circ} \mathrm{E}\right)$ for monitoring water vapour and cirrus distributions in the subtropical upper troposphere: preliminary analyses and description of a future system, Atmos. Meas. Tech., 5, 1333-1348, doi:10.5194/amt-5-1333-2012, 2012.

Hoareau, C., Keckhut, P., Noel, V., Chepfer, H., and Baray, J.L.: A decadal cirrus clouds climatology from ground-based and spaceborne lidars above the south of France $\left(43.9^{\circ} \mathrm{N}-5.7^{\circ} \mathrm{E}\right)$, Atmos. Chem. Phys., 13, 6951-6963, doi:10.5194/acp-13-69512013, 2013.

Immler, F. and Schrems, O.: Lidar measurements of cirrus clouds in the northern and southern midlatitudes during INCA $\left(55^{\circ} \mathrm{N}\right.$, 
$53^{\circ} \mathrm{S}$ ): A comparative study. Geophys. Res. Lett., 29, 1809, doi:10.1029/2002GL015077, 2002.

Immler, F., Treffeisen, R., Engelbart, D., Krüger, K., and Schrems, O.: Cirrus, contrails, and ice supersaturated regions in high pressure systems at northern mid latitudes, Atmos. Chem. Phys., 8, 1689-1699, doi:10.5194/acp-8-1689-2008, 2008.

Jolliffe, I. T.: Principal Component Analysis, Springer, 502 pp., New York, 1986.

Keckhut, P., Hauchecorne, A., Bekki, S., Colette, A., David, C., and Jumelet, J.: Indications of thin cirrus clouds in the stratosphere at mid-latitudes, Atmos. Chem. Phys., 5, 3407-3414, doi:10.5194/acp-5-3407-2005, 2005.

Keckhut, P., Borchi, F., Bekki, S., Hauchecorne, A., and SiLaouina, M.: Cirrus classification at mid-latitude from systematic lidar observations, J. App. Meteorol. Clim., 45, 249-258, 2006.

Khvorostyanov, V. I. and Sassen, K.: Microphysical processes in cirrus and their impact on radiation: a mesoscale modeling perspective, Lynch, D. K., Sassen, K., Starr, D. O'C., and Stephens, G., Cirrus, Oxford University Press, 397-432, 2002.

Lanzante, J. R.: Resistant, Robust and non-parametric techniques for the analysis of climate data: theory and examples, including applications to historical radiosonde station data, Int. J. Climatol., 16, 1197-1226, 1996.

Lohmann, U., Karcher, B., and Hendricks, J.: Sensitivity studies of cirrus clouds formed by heterogeneous freezing in the ECHAM GCM, J. Geophys. Res., 109, D16204, doi:10.1029/2003JD004443, 2004.

Luo, Z. and Rossow, W. B.: Characterizing Tropical Cirrus Life Cycle, Evolution, and Interaction with Upper-Tropospheric Water Vapor Using Lagrangian Trajectory Analysis of Satellite Observations, J. Climate, 17, 4541-4563, doi:10.1175/3222.1, 2004.

Miloshevich, L. M., Vömel, H., Whiteman, D. N., and Leblanc, T.: Accuracy assessment and correction of Vaisala RS92 radiosonde water vapor measurements, J. Geophys. Res., 114, D11305, doi:10.1029/2008JD011565, 2009.

Montoux, N., Keckhut, P., Hauchecorne, A., Jumelet, J., Brogniez, H., and David, C.: Isentropic modeling of a cirrus cloud event observed in the midlatitude upper troposphere and lower stratosphere, J. Geophys. Res., 115, D02202, doi:10.1029/2009JD011981, 2010.

Lakkis, S., Lavorato, M., Canziani P., and Lacomi, H.: Cirrus Clouds and Multiple Tropopause Events over Buenos Aires, Atmospheric and Climate Sciences, 1, 113-119, doi:10.4236/acs.2011.13013, 2011.

Luo, Z. and Rossow, W. B.: Characterizing Tropical Cirrus Life Cycle, Evolution, and Interaction with Upper-Tropospheric Water Vapor Using Lagrangian Trajectory Analysis of Satellite Observations, J. Clim., 17, 4541-4563, 2004.

Platt, C. M. R. and Dilley, A. C.: Determination of the cirrus particle single-scattering phase function from lidar and solar radiometric data, Appl. Opt., 23, 380-386, 1984.

Platt, C. M. R., Young, S. A., Austin, R. T., Patterson, G. R., Mitchell, D. L., and Miller, S. D.: LIRAD observations of tropical cirrus clouds in MCTEX. Part I: Optical properties and detection of small particles in cold cirrus, J. Atmos. Sci., 59, 31453162, 2002.

Reichardt, J.: Optical and geometrical properties of northern midlatitude cirrus clouds observed with a UV Raman lidar, Phys. Chem. Earth Pt. B, 24, 255-260, 1999.
Riihimaki, L. D. and McFarlane, S. A.: Frequency and morphology of tropical tropopause layer cirrus from CALIPSO observations: Are isolated cirrus different from those connected to deep convection?, J. Geophys. Res., 115, D18201, doi:10.1029/2009JD013133, 2010.

Sassen, K. and Cho, B. Y.: Subvisual-thin cirrus lidar dataset for satellite verification and climatological research, J. Appl. Meteorol., 31, 1275-1285, 1992.

Sassen, K. and Campbell, J. R.: A midlatitude cirrus cloud climatology from the Facility for Atmospheric Remote Sensing, Part I: Macrophysical and synoptic properties, J. Atmos. Sci., 58, 481496, 2001

Sassen, K. and Comstock, J. M.: A midlatitude cirrus cloud climatology from the Facility for Atmospheric Remote Sensing, Part III: Radiative properties, J. Atmos. Sci., 58, 2113-2127, 2001.

Sassen, K., Wang, Z., and Liu, D.: Cirrus clouds and deep convection in the tropics: Insights from CALIPSO and CloudSat, J. Geophys. Res., 114, D00H06, doi:10.1029/2009JD011916, 2009.

Seifert, P., Ansmann, A., Müller, D., Wandinger, U., Althausen, D., Heymsfeld, A. J., Massie, S. T., and Schmitt, C.: Cirrus optical properties observed with lidar, radiosonde, and satellite over the tropical Indian Ocean during the aerosol-polluted northeast and clean maritime southwest monsoon, J. Geophys. Res., 112, D17205, doi:10.1029/2006JD008352, 2007.

Solomon, S., Qin, D., Manning, M., Alley, R. B., Berntsen, T., Bindoff, N. L., Chen, Z., Chidthaisong, A., Gregory, J. M., Hegerl, G. C., Heimann, M., Hewitson, B., Hoskins, B. J., Joos, F., Jouzel, J., Kattsov, V., Lohmann, U., Matsuno, T., Molina, M., Nicholls, N., Overpeck, J., Raga, G., Ramaswamy, V., Ren, J., Rusticucci, M., Somerville, R., Stocker, T. F., Whetton, P., Wood R. A., and Wratt, D.: Technical Summary, in: Climate Change 2007: The Physical Science Basis, Contribution of Working Group I to the Fourth Assessment Report of the Intergovernmental Panel on Climate Change, edited by: Solomon, S., Qin, D., Manning, M., Chen, Z., Marquis, M., Averyt, K. B., Tignor, M., and Miller, H. L., Cambridge University Press, Cambridge, UK and New York, NY, USA, 2007.

Ström, J., Seifert, M., Kärcher, B., Ovarlez, J., Minikin, A., Gayet, J.-F., Krejci, R., Petzold, A., Auriol, F., Haag, W., Busen, R., Schumann, U., and Hansson, H. C.: Cirrus cloud occurrence as function of ambient relative humidity: a comparison of observations obtained during the INCA experiment, Atmos. Chem. Phys., 3, 1807-1816, doi:10.5194/acp-3-1807-2003, 2003.

Sunilkumar, S. V., Parameswaran, K., Rajeev, K., Krishna Murthy, B. V., Meenu, S., Sanjay K. Mehta, Asha Babu: Semitransparent cirrus clouds in the tropical tropopause layer during two contrasting seasons, J. Atmos. Sol.-Terr. Phy., 72, 745-762, 2010.

Van de Hulst, J. C.: Light Scattering by Small Particles (New York: Dover), 1957.

Wandinger, U.: Multiple-scattering influuence on extinction- and backscatter-coefficient measurements with Raman and highspectral resolution lidars, Appl. Opt., 37, 417-427, 1998.

Wang, Z. and Sassen, K.: Cirrus cloud microphysical property retrieval using lidar and radar measurements: II, Midlatitude cirrus microphysical and radiative properties, J. Atmos. Sci., 59, 22912302, 2002.

Ward, J. H.: Hierarchical grouping to optimize an objective function, J. Am. Stat. Assoc., 58, 236-244, 1963. 
Whiteman, D. N., Demoz, B., and Wang, Z.: Subtropical cirrus cloud extinction to backscatter ratios measured by $\mathrm{Ra}-$ man Lidar during CAMEX-3, Geophys. Res. Lett., 31, L12105, doi:10.1029/2004GL020003, 2004.

WMO: Meteorology - A three-dimensional science, WMO Bull., 6 (October), 134-138, 1957.
Zhang, M. H., Lin, W. Y., Klein, S. A., Bacmeister, J. T., Bony, S., Cederwall, R. T., Del Genio, A. D., Hack, J. J., Loeb, N. G., Lohmann, U., Minnis, P., Musat, I., Pincus, R., Stier, P., Suarez, M. J., Webb, M. J., Wu, J. B., Xie, S. C., Yao, M. S., and Zhang, J. H.: Comparing clouds and their seasonal variations in 10 atmospheric general circulation models with satellite measurements, J. Geophys. Res., 110, D15S02, doi:10.1029/2004JD005021, 2005. 